\title{
Dos Tratados Internacionais: o Procedimento para a Sua Elaboração e a Existência de Pressuspostos Formalísticos para a Concretização de Uma Denúncia sob o Prisma da Constituição de 1980
}

\section{LUCIANO ELIAS REIS}

Mestre em Direito Econômico pela PUCPR; Professor de Direito Administrativo do Unicuritiba; Coordenador da Especialização em Direito Municipal na UTP.

Submissão: 12.12 .2012

Decisão Editorial: 14.12 .2012

RESUMO: 0 artigo analisa inicialmente os tratados internacionais e a sua importância para as relações estrangeiras na atual conjuntura mundial. Nesse sentido, elucidam-se quais os principais benefícios desses tratados para o desenvolvimento das relações estrangeiras, principalmente com 0 avanço da informatização.

Posteriormente, discorre-se sobre o procedimento adequado para a existência e vigência dos tratados sob a luz da Constituição Federal de 1988, sendo que neste ponto examina-se a participação do Congresso Nacional para a formalização de um tratado. Nesse compasso, aproveita-se do conceito de ato administrativo complexo do direito administrativo para compreender o procedimento adotado pela Constituição de 1988 sobre os tratados internacionais.

Ao final, investiga-se a factibilidade de o procedimento para a extinção dos tratados internacionais firmados pelo Brasil ser o mesmo daquele prescrito para a sua formalização ou não.

PALAVRAS-CHAVE: Tratados internacionais; extinção; procedimento.

ABSTRACT: The article first analyses international treaties and its importance to foreign relations in the current world situation. In this sense, it is necessary to clarify what are the main benefits of these treaties for the development of foreign relations, especially after the advance of computerization.

Later, will be exposed the proper procedure of existence and validity of treaties in the light of the Constitution of 1988, and also will be examined the National Congress' participation for the formalization of a treaty. In order to take advantage of the concept of administrative complex act from Administrative Law to understand the procedure adopted by the 1988 Constitution of international treaties.

In the end, will be investigated the feasibility of termination's procedure of international treaties signed by Brazil to be the same as that prescribed for the formalization or not.

KEYWORDS: International treaties; extinction; procedure.

SUMÁRIO: Introdução; 1 Tratados internacionais; 2 Procedimento para existência e vigência dos tratados; 3 Extinção do tratado; 3.1 A denúncia e a necessidade de pressuposto formalístico para a sua concretização; Conclusão; Referências. 


\section{INTRODUÇÃOO}

Os tratados internacionais apresentam-se como a principal fonte do direito internacional nos últimos tempos. São diversas as denominações usadas para demonstrar atos que são convencionados por Estados e regidos pelo direito internacional.

Todavia, o procedimento para a confecção de um tratado e sua vigência são marcados por diversas peculiaridades, as quais são bem conflituosas do ponto de vista doutrinário, o que per si demonstra a riqueza do tema para estudo.

Em que pese as peculiaridades durante a confecção de um tratado, o ensaio em lume tem por desidério trabalhar a existência ou não de pressupostos formalísticos para a realização de denúncia de tratados internacionais por parte do Estado brasileiro.

Pode o Poder Executivo, por intermédio do seu Presidente, simplesmente denunciar um tratado que tenha sido aprovado e referendado pelo Congresso Nacional, conforme os ditames da Constituição da República Federativa de 1988.

O tema não é pacificado e este estudo nem tem o condão de exaurir a discussão nestes breves comentários, mas sim almeja fomentar a reflexão sobre o tema com foco na atuação conjunta e harmônica dos Poderes Executivo e Legislativo no Estado brasileiro.

\section{TRATADOS INTERNACIONAIS}

Os tratados internacionais refletem uma realidade e uma necessidade na atual conjuntura dos países do mundo. As origens de tais tratados não remontam somente a realidade atual ou de séculos recentes. Tem-se notícia que o acordo mais antigo é da época de 3.200 a.C. entre as cidades de Lagash e Umma, envolvendo questões fronteiriças ${ }^{1}$.

Os mais variados acordos, cartas, protocolos, declarações, convenções, pactos, avenças, podem ser denominados de tratados internacionais. Sem apegar qualquer diferença nominal ou substancial dos acordos, convenções e avenças entre os países, para fins do presente estudo, utilizar-se-á a denominação de tratados, englobando todas as espécies ora suscitadas. O uso deste referencial terminológico está baseado na premissa de que tratado "é todo acordo formal concluído entre sujeitos de direito internacional público e destinado a produzir efeitos jurídicos" ${ }^{\prime 2}$.

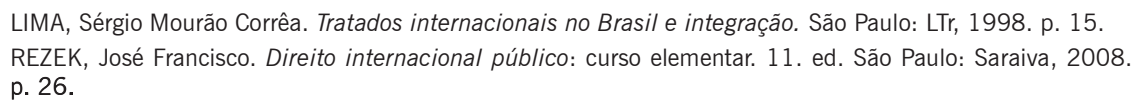




\section{Para Louis Henkin:}

O termo "tratado" é geralmente usado para se referir aos acordos obrigatórios celebrados entre sujeitos de direito internacional que são regulados pelo direito internacional. Além do termo "tratado", diversas outras denominações são usadas para se referir aos acordos internacionais. As mais comuns são convenção, pacto, protocolo, carta, convênio, como também tratado ou acordo internacional. Alguns termos são usados para denotar solenidade (por exemplo, pacto ou carta) ou a natureza suplementar do acordo (protocolo). ${ }^{3}$

Segundo a Convenção de Viena sobre o Direito dos Tratados, tratado "significa um acordo internacional concluído por escrito entre Estados e regido pelo Direito Internacional, quer conste de um instrumento único, quer de dois ou mais instrumentos conexos, qualquer que seja sua denominação específica" (art. $2^{\circ}$, I, alínea a).

Quanto à importância dos tratados, pode-se dizer que dois fenômenos demonstram a importância dos tratados internacionais, segundo Francisco Rezek:

[...] a entrada em cena das organizações internacionais, no primeiro pós-guerra - fazendo com que o rol das pessoas jurídicas de direito das gentes, habilitadas a pactuar no plano exterior, já não mais se exaurisse nos Estados soberanos -; e a codificação do direito dos tratados, tanto significando a transformação de suas regras costumeiras em regras convencionais, escritas, expressas, elas mesmas no texto de um tratado. ${ }^{4}$

Na mais recente atualidade (1970 em diante), pode-se dizer que a importância dos tratados internacionais sobressai também em razão da diminuição das fronteiras entre os mais variados países, seja em razão da informatização ou facilidade de locomoção.

Fala-se em informatização, pois hodiernamente a informatização estreitou os relacionamentos entre pessoas que estão a milhares de quilômetros de distância. Ou seja, um simples computador conectado com a Internet permite que uma pessoa do Brasil comunique-se de modo instantâneo com outra pessoa na Austrália. Ante essa facilidade, não se pode perder de vista que tais relacionamentos nem sempre serão pacíficos, consensuais e sem possíveis celeumas. Nesse panorama fático, os tratados podem ser utilizados para fins de normatização e consequente regulamentação das relações. Impende alvitrar também que não há necessidade de conflitos imediatos para destacar a importância dos tratados, visto que estes servem para nortear a atuação das pessoas.

3 HENKIN, Louis. International law: politics, values and principles. Boston: Martinus Nijhoff, 1990. p. 416 Apud PIOVESAN, Flávia. Direitos humanos e o direito constitucional internacional. 9. ed. São Paulo: Saraiva, 2008. p. 44.

4 REZEK, José Francisco. Op. cit., p. 13. 
Sobre a revolução da informática, valioso lembrar-se do estudo elaborado por Frijtof Capra, o qual descreve que:

A característica comum aos múltiplos aspectos da globalização é uma rede global de informática e comunicações baseada no uso de tecnologias novas e revolucionárias. A revolução de informática é o resultado de uma complexa dinâmica de interações tecnológicas e humanas que gerou efeitos sinérgicos em três grandes setores da eletrônica - os computadores, a microeletrônica e as telecomunicações. As principais inovações que criaram o ambiente eletrônico radicalmente novo dos anos de 1990 ocorreram todas vinte anos antes, na década de $1970 .^{5}$

Quanto à facilidade de locomoção, resta indissociável lembrar este aspecto, pois é primordial para a criação e validade dos tratados internacionais para a regulação de atividades e de pessoas. Antigamente, não se vislumbrava como factíveis meios de locomoção tão acessíveis e eficazes para a feitura de viagens e deslocamentos extensos. A concepção de distância configurava, às vezes, como verdadeiro obstáculo instransponível para a realização de acordos, convenções ou tratados em si. Não se está aqui afastando a existência de tratados antigamente, mas sim descrevendo que a diminuição da distância contribuiu para o fomento de novos tratados.

Postos esses breves comentários, verifica-se que os tratados internacionais significam a principal fonte do direito internacional.

Nesse sentido, Flávia Piovesan afirma que "os tratados internacionais, enquanto acordos internacionais juridicamente obrigatórios e vinculantes (pacta sunt servanda) constituem hoje a principal fonte de obrigação do direito internacional" ${ }^{\prime \prime}$.

Ademais, como fontes de direito internacional, os tratados são "considerados atualmente a fonte mais importante do $\mathrm{DI}$, não devido à sua multiplicidade, mas também porque geralmente as matérias mais importantes são regulamentadas por eles" ${ }^{\prime \prime}$.

O destaque dos tratados internacionais para o direito internacional, segundo Flávia Piovesan, é exteriorizado pelo enfoque do positivismo internacional, o que estampa uma superação do positivismo ao costume que até então era a principal fonte de obrigação do direito internacional ${ }^{8}$.

Vale apontar que, conforme bem alertado por Flávia Piovesan, "não necessariamente os tratados internacionais consagram novas regras de direito in-

5 CAPRA, Fritjof. As conexões ocultas: ciência para uma vida sustentável. Trad. Marcelo Brandão Cipolla. São Paulo: Cultrix, 2002. p. 144.

6 PIOVESAN, Flávia. Op. cit., p. 43.

7 MELLO, Celso D. de Albuquerque. Curso de direito internacional público. 15. ed. Rio de Janeiro: Renovar, 2004. p. 212.

8 Idem. 
ternacional. Por vezes, acabam por codificar regras preexistentes consolidadas pelo costume internacional, ou, ainda, optam por modificá-la" ${ }^{\prime \prime}$.

Ainda que sejam correlacionados ao direito internacional, indissociável aliar os tratados ao direito civil. Nessa senda, Sérgio Mourão Corrêa Lima explicita as semelhanças que guardam entre o contrato típico do direito civil e os tratados do direito internacional. O autor deixa claro que os mesmos princípios informadores dos contratos aplicam-se aos tratados, quais sejam, o princípio da autonomia da vontade no momento da formação do contrato e o princípio pacta sunt servanda quando da celebração e aplicação do contrato ${ }^{10}$.

\section{PROCEDIMENTO PARA EXISTÊNCIA E VIGÊNCIA DOS TRATADOS}

Os tratados internacionais possuem um procedimento para a sua existência, celebração e vigência"1. Pode-se utilizar o termo "procedimento" em acepção similar àquela utilizada pelo direito administrativo, qual seja, uma série de atos concatenados objetivando ao seu final um determinado resultado ${ }^{12}$. A grande distinção que se coloca aqui para emprestar o conceito arraigado ao direito administrativo de modo integral é a sucessão de "atos administrativos", bem como a própria denotação de "procedimento administrativo". Portanto, para fins da existência e vigência de um tratado internacional, pode-se abstrair o adjetivo "administrativo", ou seja, somente alude-se como procedimento em si.

Passada essa preliminar, insta destacar que o primeiro ato a ser realizado para a existência de um tratado é a negociação. Por intermédio da negociação os Estados iniciam as conversas e as transações, a fim de colimarem um determinado grupo com objetivos comuns.

O plano negocial de um tratado é tão importante quanto a negociação de um contrato, haja vista que, neste momento, sucederá as discussões e elucubrações acerca dos objetivos, dos meios a serem utilizados, da forma, das cláusulas a serem estipuladas, etc. A partir da negociata, as partes envolvidas iniciam, inclusive, a analisar se o tratado será de seu real interesse.

Sérgio Mourão Corrêa Lima enaltece que "dentre os pontos que podem consistir em objeto de negociação está a fixação do quorum de ratificação do

9 PIOVESAN, Flávia. Op. cit., p. 44.

10 LIMA, Sérgio Mourão Corrêa. Op. cit., p. 19.

11 Não se está falando da validade do tratado. Sobre a validade do tratado, lembra-se da lição de Hildebrando Accioly, Geraldo Eulálio do Nascimento Silva e Paulo B. Casella que descrevem as condições para a validade do tratado: capacidade das partes; agentes habilitados, consentimento mútuo e que o objeto seja lícito e possível. (ACCIOLY, Hidelbrando; SILVA, Geraldo Eulálio do Nascimento; CASELLA, Paulo B. Manual de direito internacional público. 17. ed. São Paulo: Saraiva, 2009. p. 135 e seguintes)

12 Alvitra-se que processo administrativo é uma sucessão de atos administrativos sequenciais e concatenados objetivando um resultado final, permeado pela existência de sujeitos e contraditório. Já procedimento administrativo é a sucessão de atos administrativos concatenados objetivando um resultado final, sendo que não indispensavelmente possui sujeitos e contraditório. Sobre o assunto, vide BACELLAR FILHO, Romeu Felipe. Reflexões sobre direito administrativo. Belo Horizonte: Fórum, 2009. p. 79-124. 
tratado. Os Estados que estejam participando da negociação podem estipular necessária a ratificação por parte de um número determinado de Estados, para que o tratado ganhe vigência no plano internacional"13.

Normalmente as negociações acontecem em assembleias e reuniões, as quais são devidamente organizadas, bem como formalizadas pelas partes, até para que as tratativas ali travadas sejam honradas na redação do tratado, evitando assim esquecimentos ou substituição das vontades expostas nas citadas reuniões.

Após as negociatas, tem-se o momento inaugural no plano internacional, qual seja, a assinatura do tratado.

A assinatura do tratado não significa que o texto começa a irradiar integralmente os seus efeitos de imediato. A assinatura é o ato pelo qual os Estados, por intermédio dos seus representantes, subscrevem a vontade dos referidos entes, a fim de se unir com outros para o alcance de alguns objetivos, os quais deverão estar devidamente expressados.

Flávia Piovesan expressa, de maneira ímpar, que a assinatura do tratado é um "aceite precário e provisório, não irradiando efeitos jurídicos vinculantes. Trata-se de mera aquiescência do Estado em relação à forma e ao conteúdo final do tratado. A assinatura do tratado, via de regra, indica tão somente que o tratado é autêntico e definitivo"14.

Por fins didáticos, colaciona-se ainda uma passagem de Aréchaga que demonstra quais são os fatores preponderantes para a assinatura do tratado:

2

a) autentica o texto do tratado;

b) atesta que os negociadores estão de acordo com o texto do tratado;

c) os dispositivos referentes ao prazo para a troca ou o depósito dos instrumentos de ratificação e a adesão são aplicados a partir da assinatura;

d) os contratantes "devem se abster de atos que afetem substancialmente o valor do instrumento assinado". A Convenção de Viena (art. 18, b) abre uma exceção para a obrigação de uma parte "não frustrar o objeto e finalidade de um tratado", que é a de que a "entrada em vigor do tratado" não tenha sido "retardada indevidamente". Maresca assinala que nos tratados bilaterais uma parte que tenha assinado o tratado e este não tenha entrado em vigor pode praticar atos contrários ao tratado, desde que após a assinatura comunique previamente ao outro contratante que não mais concorda com o que ele assinara;

e) a assinatura pode ter valor político;

13 LIMA, Sérgio Mourão Corrêa. Op. cit., p. 22

14 PIOVESAN, Flávia. Op. cit., p. 47. 
f) pode significar que o Estado reconhece as normas costumeiras tornadas convencionais. ${ }^{15}$

Inequívoco que a assinatura representa a manifestação de interesse do Estado na subscrição de um tratado, o que per si adentra à boa-fé internacional, salvo se o próprio texto do tratado dispuser algo específico atinente à assinatura. Inclusive, quanto à assinatura, o Tratado de Viena expõe que, a rigor, a assinatura transluz o consentimento do Estado ${ }^{16}$.

No direito interno brasileiro, a responsabilidade para a assinatura do tratado é do Presidente da República. Para chegar a essa solução, deve-se recorrer à Carta Magna, a qual estabeleceu em seu art. 84, VII e VIII, determinando que compete exclusivamente ao Presidente da República manter relações com Estados estrangeiros e acreditar seus representantes diplomáticos, bem como celebrar tratados, convenções e atos internacionais, sujeitos a referendo do Congresso Nacional.

Imperioso apontar que, no momento da assinatura, poderá o chefe do Poder Executivo brasileiro realizar a assinatura com reservas.

As reservas importam em expressar uma declaração unilateral, qualquer que seja a sua redação ou denominação, feita por um Estado ao assinar, ratificar, aceitar ou aprovar um tratado, ou a ele aderir, com o objetivo de excluir ou modificar o efeito jurídico de certas disposições do tratado em sua aplicação a esse Estado (art. 2oㅜ 1 , alínea $d$ ).

Ou seja, na verdade, os Estados poderão participar de um tratado sem necessariamente aderi-lo integralmente. Poderá, por vezes, algumas partes serem contrárias aos interesses de um Estado ou ainda não ser de interesse em si subscrever in totum, razão pela qual legitimará a subscrição com reservas.

Segundo Sérgio Mourão Corrêa Lima, "os Estados que tomaram parte na negociação do tratado internacional podem não estar de acordo com todo o seu

15 Aréchaga apud MELLO, Celso D. de Albuquerque. Op. cit., p. 226-227.

16 "Art. 12. Consentimento em obrigar-se por um Tratado Manifestado pela Assinatura:

1. O consentimento de um Estado em obrigar-se por um tratado manifesta-se pela assinatura do representante desse Estado:

a) quando o tratado dispõe que a assinatura terá esse efeito;

b) quando se estabeleça, de outra forma, que os Estados negociadores acordaram em dar à assinatura esse efeito; ou

c) quando a intenção do Estado interessado em dar esse efeito à assinatura decorra dos plenos poderes de seu representante ou tenha sido manifestada durante a negociação.

2. Para os efeitos do parágrafo 1 :

a) a rubrica de um texto tem o valor de assinatura do tratado, quando ficar estabelecido que os Estados negociadores nisso concordaram;

b) a assinatura ad referendum de um tratado pelo representante de um Estado, quando confirmada por esse Estado, vale como assinatura definitiva do tratado." 
conteúdo. Assim, deixam de manifestar seu consentimento quanto aos dispositivos com os quais não concordem"1"17.

A reserva é uma declaração unilateral do Estado, que tem por escopo excluir ou modificar os efeitos jurídicos de uma ou várias disposições do tratado e sua aplicação frente a esse Estado.

Sobre a reserva, o Tratado de Viena estipula em seu art. 19 que o Estado pode, ao assinar, ratificar, aceitar ou aprovar um tratado, ou a ele aderir, formular uma reserva, salvo nos casos em que a reserva seja proibida pelo tratado; o tratado disponha que só possam ser formuladas determinadas reservas, entre as quais não figure a reserva em questão; ou nos casos em que a reserva seja incompatível com o objeto e a finalidade do tratado.

Além disso, o Tratado de Viena reza também acerca da aceitação das reservas, objeções e processo relativo às reservas (arts. 19 a 23).

Celso D. de Albuquerque Mello raciocina que as reservas, para serem válidas, precisam preencher uma condição de forma e outra de fundo. Para ele, "a condição de forma é que ela deve ser apresentada por escrito pelo poder competente dentro do Estado para o trato dos assuntos internacionais, isto é, pelo Poder Executivo. O Legislativo não pode apresentar reservas no plano internacional. A condição de fundo é a aceitação da reserva pelos outros contratantes ${ }^{\prime 18}$.

Trespassadas as negociações e assinado o tratado, há a fase da aprovação do texto de acordo com o ordenamento jurídico interno do Estado signatário ${ }^{19}$.

No âmbito brasileiro, inicia-se uma grande discussão acerca da competência para a aprovação do tratado, mais precisamente para saber se o Poder Executivo precisa ou não da autorização do Congresso Nacional como condição para a validade da celebração de qualquer tratado internacional.

A Constituição de 1988 preconiza, em seu art. 84, VIII, in verbis:

Art. 84. Compete privativamente ao Presidente da República:

$[\ldots]$

VIII - celebrar tratados, convenções e atos internacionais, sujeitos a referendo do Congresso Nacional.

Já o art. 49, inciso I, da Carta Maior estipula que:

Art. 49. É da competência exclusiva do Congresso Nacional:

17 LIMA, Sérgio Mourão Corrêa. Op. cit., p. 23.

18 MELLO, Celso D. de Albuquerque. Op. cit., p. 247.

19 No tocante aos efeitos, vale destacar que para o plano internacional os requisitos são: a aprovação no plano interno, a ratificação no plano externo e o atendimento do quórum para que o tratado possa irradiar os seus efeitos colimados. 
I - resolver definitivamente sobre tratados, acordos ou atos internacionais que acarretem encargos ou compromissos gravosos ao patrimônio nacional;

$[\ldots]$

Pela intelecção normativa, infere-se, de modo imediato, que a grande problemática se deve ao fato de a prescrição constitucional nos citados dispositivos ter inserido no art. 49 a expressão "que acarretem encargos ou compromissos gravosos ao patrimônio nacional".

A dúvida paira na seguinte esteira: compete ao Congresso Nacional tão somente manifestar-se sobre os tratados, acordos ou atos internacionais que acarretem encargos ou compromissos gravosos ao patrimônio nacional? Ou compete ao Congresso Nacional referendar qualquer tratado, acordo ou ato internacional? Isso representa que existe o questionamento acerca da compulsoriedade absoluta da deliberação do Congresso Nacional em todos os tratados ou não.

Para iniciar o debate, faz-se necessário relembrar das críticas de Antônio Paulo Cachapuz de Medeiros, o qual diz que "a Constituição de 1988 perdeu a oportunidade para disciplinar de forma moderna e clara a competência para celebrar tratados e ampliou ainda mais as divergências sobre o tema"20.

Procurar-se-á explanar o posicionamento de alguns estudiosos do tema, a fim de externar tal embate, para posteriormente chegar à conclusão necessária aos propósitos deste artigo.

Manoel Gonçalves Ferreira Filho assevera que o Congresso Nacional deverá necessariamente referendar os tratados internacionais ${ }^{21}$, sob pena de invalidade dos tratados perante o ordenamento jurídico interno brasileiro. O jurista expõe que "a vontade do Estado brasileiro, relativamente a atos internacionais, inclusive a tratados e a convenções, surge de um ato complexo, onde se integram a vontade do Presidente da República, que os celebra, e a do Congresso Nacional, que os ratifica" 22 .

Na mesma diretriz, Pinto Ferreira assevera que "é necessária a aprovação dos acordos executivos pelo Congresso Nacional, salvo emenda constitucional que discipline a matéria, como na França" ${ }^{\prime 23}$.

20 MEDEIROS, Antonio Paulo Cachapuz de. O poder de celebrar tratados: competência dos poderes constituídos para a celebração de tratados à luz do direito internacional, do direito comparado e do direito constitucional brasileiro. Porto Alegre: S. A. Fabris, 1995. p. 383.

21 No mesmo sentido, vide J. Cretella Júnior (Comentários à Constituição Brasileira de 1988. Rio de Janeiro: Forense, 1992. p. 2533-2534).

22 FERREIRA FILHO, Manoel Gonçalves. Comentários à Constituição Brasileira de 1988. São Paulo: Saraiva, v. II, 1992. p. 21.

23 FERREIRA, Pinto. Comentários à constituição brasileira. São Paulo: Saraiva, v. III, 1992. p. 570. 
Para Luis Ivani de Amorim Araújo ${ }^{24}$, a aprovação é um imperativo categórico, o que per si dispensa qualquer elucubração acerca da questão.

De modo integralmente oposto, há diversos doutrinadores que defendem que os acordos internacionais atrelam-se à competência privativa do Poder Executivo, não sendo racional e quiçá lógico que o Poder Legislativo tenha que participar.

Celso D. de Albuquerque Mello defende a ideia de que o Poder Executivo não precisa recorrer ao Poder Legislativo para a aprovação de um tratado internacional, isso porque a autonomia e competência é do Poder Executivo, o que per si dispensa a necessidade de oitiva e aprovação do Congresso, sendo que inclusive esse posicionamento é a alternativa que melhor atende às finalidades práticas ${ }^{25}$.

Na mesma linha, Sette Câmara aduz que:

[...] parece evidente que o Congresso Nacional só tem competência exclusiva para "decidir definitivamente" sobre tratados e atos internacionais quando esses "acarretem encargos e compromissos gravosos ao patrimônio nacional". A decisão sobre qualquer outro tratado, por maior que seja a sua importância, passa a ser da competência exclusiva do Executivo. Se o "patrimônio nacional" não for de qualquer modo atingido, o Executivo tem as mãos livres para ratificar qualquer tratado independentemente de aprovação legislativa. ${ }^{26}$

Hildebrando Accioly, Geraldo Eulálio do Nascimento e Paulo B. Casella advogam que quando

o compromisso verse sobre matéria executiva, não há razão para que este seja submetido ao poder legislativo. Isso tem sido reconhecido, desde muito, por exemplo, nos Estados Unidos, onde a prática dos acordos executivos já recebeu a consagração da própria Suprema Corte, apesar do que dispõe a Constituição americana em relação aos tratados. ${ }^{27}$

De forma um pouco diversa, Vicente Marotta Rangel, na qualidade de consultor jurídico do Itamaraty, teve a oportunidade de manifestar-se sobre o tema. À época, Marotta Rangel interpretou que inexiste qualquer antinomia jurídica entre o art. 49, I, e o art. 84, VIII, da Constituição Federal de 1988, e que se deve interpretar harmonicamente os dispositivos constitucionais, deve-se relembrar o contexto histórico que ensejou a Constituição de 1988, bem como se deve pensar sobre o papel do Congresso Nacional acerca da criação das normas jurídicas no âmbito brasileiro.

24 ARAÚJO, Luís Ivani de Amorim. Curso de direito internacional público. 7. ed. Rio de Janeiro: Forense, 1992. p. 43.

25 MELLO, Celso D. de Albuquerque. Op. cit., p. 237.

26 José Sette Câmara apud MEDEIROS, Antonio Paulo Cachapuz de. Op. cit., p. 387.

27 ACCIOLY, Hidelbrando; SILVA, Geraldo Eulálio do Nascimento; CASELLA, Paulo B. Op. cit., p. 141. 
Por essas razões, Marotta Rangel assenta que ao Congresso Nacional não se deve submeter tão apenas os tratados, acordos ou atos internacionais que acarretem encargos ou compromissos gravosos ao patrimônio nacional. Todavia, isso também não significa que todos os tratados devem ser submetidos ao Congresso Nacional, visto que os tratados que versarem sobre a) acordos de armistício negociados por comandantes militares no limite de suas atribuições; b) acordos de mera interpretação ou mera suplementação de anteriores, já aprovados pelo Poder Legislativo; c) acordos que se restringem à declaração e à formulação de bases de futuras negociações; e d) acordos caracterizados por reversibilidade; todos esses poderão ser aprovados pelo Poder Executivo sem a necessidade de participação do Poder Legislativo ${ }^{28}$.

Antônio Paulo Cachapuz de Medeiros, após estudo sobre os métodos modernos de interpretação, concluiu que:

Do ponto de vista histórico-teleológico, a conclusão só pode ser que o legislador constituinte desejou estabelecer a obrigatoriedade do assentimento do Congresso para os tratados internacionais, dando ênfase para aqueles que acarretarem encargos, gravames, ônus financeiros, para o patrimônio nacional.

Do ponto de vista lógico-sistemático, há que se considerar que os dispositivos em questão fazem parte do mesmo título da Constituição (Da Organização dos Poderes) e são como que as duas faces de uma mesma moeda: o art. 84, VIII, confere ao Presidente da República o poder de celebrar tratados, convenções e atos internacionais, mas especifica que estão todos sujeitos a referendo do Congresso Nacional; o art. 49, I, destaca que os tratados, acordos ou atos internacionais, assinados por quaisquer autoridades do Governo brasileiro, que acarretem encargos ou compromissos gravosos ao patrimônio nacional, precisam ser aprovados pelo Congresso. ${ }^{29}$

Dessa feita, após uma breve incursão sobre os mais variados pensamentos e interpretações de alguns pensadores do Direito, coaduna-se da posição de que a interpretação lógico-sistemática ${ }^{30}$ proposta por Antônio Paulo Cachapuz de Medeiros é a mais coerente e escorreita no uso dos métodos de interpretação previstos na doutrina.

Assentindo com essa linha, Flávia Piovesan deixa bem claro que os tratados internacionais "demandam, para seu aperfeiçoamento, um ato complexo no qual se integram a vontade do Presidente da República, que os celebra, e a do Congresso Nacional, que os aprova, mediante Decreto Legislativo"31.

28 Vicente Marotta Rangel apud MEDEIROS, Antonio Paulo Cachapuz de. Op. cit., p. 390-391.

29 MEDEIROS, Antonio Paulo Cachapuz de. Op. cit. p. 397.

30 Sobre o método lógico-sistemático, Paulo Bonavides lembra que "graças a esse método, que assenta objetivamente sobre relações ou interconexões de normas, pode a hermenêutica jurídica extrair diversas regras ou cânones, interpretativos fundados em argumentos lógicos (a fortiori, a contrario, sedes materiae e ab absurdo), cujo emprego é frequente da parte de quantos abraçam na interpretação das leis o critério lógico-sistemático" (BONAVIDES, Paulo. Curso de direito constitucional. 19. ed. São Paulo: Malheiros, 2006. p. 445).

31 PIOVESAN, Flávia. Op. cit., p. 48. 
Ou seja, a aprovação do tratado no âmbito normativo brasileiro considera-se um ato complexo. Utiliza-se, aqui, emprestado também do direito administrativo, o conceito de ato administrativo complexo da Maria Sylvia Zanella Di Pietro, pela qual os "atos complexos são os que resultam da manifestação de dois ou mais órgãos, sejam eles singulares ou colegiados, cuja vontade se funde para formar um ato único" ${ }^{\prime 2}$.

Por sua vez, Sérgio Mourão Corrêa Lima descreve que a aprovação do Congresso pode ser comparada a uma condição suspensiva constante de um contrato $^{33}$.

A passagem do tratado pelo Congresso Nacional é indiscutível a partir de uma interpretação sistemática da Constituição, pelo menos no nosso ponto de vista ${ }^{34}$.

Assim, trespassado pela Câmara dos Deputados com a devida aprovação, nos termos do regimento, e, em seguida, encaminhado, processado, analisado e aprovado pelo Senado, então tem-se que houve a anuência do Congresso Nacional.

O aquiescer do Congresso Nacional em conformidade com a Constituição Federal legitima então o Poder Executivo a ratificar o tratado. Contudo, para demonstrar tal assentimento, é imprescindível que seja formalizado por intermédio do competente instrumento normativo. Para tanto, há a edição de um decreto legislativo, no qual deverá haver a exposição de que o tratado foi aprovado pelo Congresso Nacional.

O exame do Poder Legislativo representa um verdadeiro controle político pelo Congresso Nacional e previsto na Constituição de 1988.

A finalidade do controle político é bem externada por Manuel Aragon, que descreve que "su objeto inmediato puede residir tanto em la actividad general de un órgano (la política del Gobierno, por ejemplo) como en una actuación específica (la actividad sectorial del Gobierno, o de outro órgano sometido a control), o en un acto político concreto e, incluso, como antes se decía, en una norma" ${ }^{\prime 35}$.

Ademais, o controle político difere do controle judicial, visto que as razões para a sua apreciação transcendem a análise jurídica em si. A interpretação, como dito por Aragon, "es enteramente libre, sustenada no en motivos de derecho, sino de oportunidad, esto es, se trata de una valoración efectuada con razones políticas y no con método jurídico ${ }^{\prime 36}$.

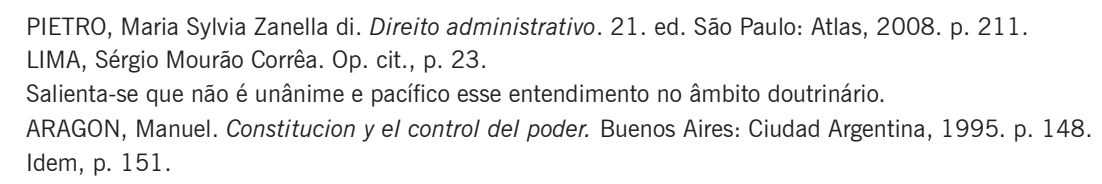


Abre-se parêntese para rechaçar o raciocínio que bastaria o aval do Congresso Nacional para que o tratado pudesse espraiar efeitos perante o ordenamento jurídico brasileiro, isto porque, consoante se explicará, é necessário que a autoridade competente (Poder Executivo brasileiro) ratifique perante o plano internacional.

Um aspecto de elevado relevo é a possibilidade ou não de os parlamentares no Congresso Nacional realizarem emendas ou reservas no tratado assinado pelo Poder Executivo.

Sérgio Mourão Corrêa Lima assevera que o Poder Legislativo possui a prerrogativa de, por via da reserva, deixar de manifestar seu aceite atinente aos dispositivos os quais discorde ${ }^{37}$.

Celso D. de Albuquerque Mello defende que a emenda apresentada pelo Congresso "é uma interferência indevida nos assuntos do Executivo, uma vez que só a ele competem negociações no domínio internacional e a emenda nada mais é do que uma forma indireta pela qual o Legislativo se imiscui na negociação" ${ }^{\prime \prime}$.

Compete explicitar que o fato de o Congresso Nacional aprovar não significa que o tratado inicia a sua vigência, pois para tanto é indispensável que haja a ratificação por parte do Executivo. Não é incomum a aprovação pelo Congresso Nacional e a não ratificação pelo Governo em situações concretas já vivenciadas. Sobre o assunto, Antônio Paulo Cachapuz Medeiros exemplifica com os seguintes casos, Convenção sobre o Mar Territorial e a Zona Contígua, sobre Alto-Mar, sobre Pesca e Conservação dos Recursos Vivos do Alto-mar e sobre a Plataforma Continental ${ }^{39}$.

A ratificação demonstra "a subsequente confirmação formal por um Estado de que está obrigado ao tratado. Significa, pois, o aceite definitivo, pelo qual o Estado se obriga pelo tratado no plano internacional. A ratificação é o ato jurídico que irradia necessariamente efeitos no plano internacional"40.

Para a plena validade da ratificação, em algumas vezes, é necessário que seja atendido o quórum previsto para tal mister. O intuito da ratificação é atribuir vigência ao tratado no plano internacional. Por outro lado, no campo interno, o acordo internacional ganha vigência com a implementação do decreto do Executivo, ratificando- ${ }^{41}$.

Nesses termos, Hildebrando Accioly, Geraldo Eulálio do Nascimento e Paulo B. Casella descrevem que a ratificação "é o ato administrativo mediante o

\footnotetext{
37 LIMA, Sérgio Mourão Corrêa. Op. cit., p. 29.

38 MELLO, Celso D. de Albuquerque. Op. cit., p. 238.

39 MEDEIROS, Antonio Paulo Cachapuz de. Op. cit., p. 469

PIOVESAN, Flávia. Op. cit., p. 47.

LIMA, Sérgio Mourão Corrêa. Op. cit., p. 33.
} 
qual o chefe de estado confirma tratado firmado em seu nome ou em nome do estado, declarando aceito o que foi convencionado pelo agente signatário"42.

O Tratado dos Tratados define a ratificação como o "ato internacional assim denominado pelo qual um Estado estabelece no plano internacional o seu consentimento em obrigar-se por um tratado" (art. 2oㅗ 1, alínea b).

Em momento posterior, o aludido tratado também dispõe sobre a ratificação, expondo que este ato representa o consentimento do Estado em obrigar-se pelas disposições pactuadas entre as partes (arts. 14 e seguintes).

A título complementar, Flávia Piovesan enfatiza claramente que aprovação e ratificação são dois atos totalmente diferentes. O primeiro ato é a aprovação do Congresso por intermédio do decreto legislativo e o segundo, a ratificação do Presidente da República com a troca ou o respectivo depósito do instrumento de ratificação ${ }^{43}$.

Sérgio Mourão Corrêa Lima alerta que, "no momento em que o Presidente da República é informado da aprovação do texto do tratado no Senado Federal, o Estado brasileiro nem sequer integra o vínculo obrigacional"44. Até porque, caso o quorum necessário não seja alcançado, então nem entrará em vigência o tratado.

Desse modo, não basta que o tratado seja aprovado, sem realizar a promulgação e publicação do mesmo. Tais atos, promulgação e publicação, revelam-se essenciais para a eficácia jurídica dos tratados. A falta de promulgação e publicação gera a ineficácia jurídica dos tratados.

Sobre o assunto, o Supremo Tribunal Federal já decidiu, mais precisamente pelo julgamento da Ação Direta de Inconstitucionalidade no 1.480-3, que é imprescindível a promulgação e publicação dos tratados celebrados no Brasil, sob pena de absoluta ineficácia jurídica do ato internacional no âmbito brasileiro.

O exame da vigente Constituição Federal permite constatar que a execução dos tratados internacionais e a sua incorporação à ordem jurídica interna decorrem, no sistema adotado pelo Brasil, de um ato subjetivamente complexo, resultante da conjugação de duas vontades homogêneas: a do Congresso Nacional, que resolve, definitivamente, mediante decreto legislativo, sobre tratados, acordos ou atos internacionais (CF, art. 49, I) e a do Presidente da República, que, além de poder celebrar esses atos de direito internacional (CF, art. 84, VIII), também dispõe - enquanto Chefe de Estado que é - da competência para promulgá-los mediante decreto. O iter procedimental de incorporação dos tratados internacionais - superadas as fases prévias da celebração da convenção internacional [...].

42 ACCIOLY, Hidelbrando; SILVA, Geraldo Eulálio do Nascimento; CASELLA, Paulo B. Op. cit., p. 141.

43 PIOVESAN, Flávia. Op. cit., p. 48.

44 LIMA, Sérgio Mourão Corrêa. Op. cit., p. 27. 
(ADIn 1.480-MC, Rel. Min. Celso de Mello, Julgamento em 04.09.1997, Plenário, DJ de 18.05.2001)

No mesmo diapasão, o Supremo Tribunal Federal, ulteriormente, posicionou-se na apreciação da Carta Rogatória no 8.279 da República Argentina, momento em que repudiou a tese daqueles que compreendem que a vigência do tratado internacional inicia-se do decreto do Senado Federal:

A recepção dos tratados internacionais em geral e dos acordos celebrados pelo Brasil no âmbito do Mercosul depende, para efeito de sua ulterior execução no plano interno, de uma sucessão causal e ordenada de atos revestidos de caráter político-jurídico, assim definidos: (a) aprovação, pelo Congresso Nacional, mediante decreto legislativo, de tais convenções; (b) ratificação desses atos internacionais, pelo Chefe de Estado, mediante depósito do respectivo instrumento; (c) promulgação de tais acordos ou tratados, pelo Presidente da República, mediante decreto, em ordem a viabilizar a produção dos seguintes efeitos básicos, essenciais à sua vigência doméstica: (1) publicação oficial do texto do tratado e (2) executoriedade do ato de direito internacional público, que passa, então - e somente então - a vincular e a obrigar no plano do direito positivo interno. Precedentes. O sistema constitucional brasileiro não consagra o princípio do efeito direto e nem o postulado da aplicabilidade imediata dos tratados ou convenções internacionais. (CR 8.279-AgRg, Rel. Min. Presidente Celso de Mello, Julgamento em 17.06.1998, Plenário, DJ de 10.08.2000)

Para ilustrar, compete informar que o instrumento de ratificação poderá ter a necessidade de ser "depositado em um órgão que assuma a custódia do instrumento - por exemplo, na hipótese de um tratado das Nações Unidas, o instrumento de ratificação deve ser depositado na própria ONU; se o instrumento for do âmbito regional interamericano, deve ser depositado na OEA ${ }^{\prime \prime 4}$. Caso não haja a imperiosidade de depósito, então o próprio tratado nada disporá ou disporá especificamente nesse sentido.

Por derradeiro, quanto à legislação vigente no Brasil, a falta de prazo para a ratificação por parte do Poder Executivo ou a ausência de prazo para aprovação ou não do Congresso Nacional revela-se como um erro crucial da nossa Constituição e não passa despercebido pelos estudiosos do Direito. Flávia Piovesan qualifica a sistemática dos nossos dispositivos constitucionais acerca do tema como "lacunosa, falha e imperfeita" 46 .

É uma situação delicada e extremamente prejudicial aos interesses da coletividade, isso porque a dependência do bel-prazer ou das preferências dos agentes políticos que estão no Congresso Nacional ou na Presidência da República acaba por vezes inclusive prejudicando o próprio desenvolvimento do 
Estado em si ou elastecendo um maior rigor na defesa dos direitos dos cidadãos que integram o Estado.

Deveria haver, no mínimo, uma previsão normativa com um prazo para que o protocolo envolvendo a apreciação do Congresso Nacional, mais precisamente tanto na Câmara dos Deputados quanto no Senado Federal, e para o posicionamento do Presidente da República para a ratificação ou não, fosse resolvido.

Não se pode preterir um tratado internacional em virtude da displicência no trato dos procedimentos que são submetidos ao Congresso Nacional ou à própria Presidência da República. Esse raciocínio também serve para refutar qualquer tentativa de barganha por parte dos agentes públicos na presteza ou lerdeza na análise de um tratado internacional.

\section{EXTINÇÃO DO TRATADO}

A extinção do tratado pode ocorrer pela vontade comum ou pela vontade unilateral (denúncia).

A vontade comum extingue um tratado por ab-rogação, sempre que a vontade de extingui-lo seja comum a todas as partes. Não necessariamente serão as mesmas partes que iniciaram o tratado, pois, entre a assinatura, vigência e o momento de extinção poderão ter adentrado ou saído diversas partes. Por essa razão, não se pode dizer que a extinção em razão da vontade comum decorrerá da volitividade das partes que ensejaram a vigência do tratado.

Segundo José Francisco Rezek, a vontade comum das partes de extinguir o tratado poderá ocorrer sob duas formas: (i) predeterminação ab-rogatória ou (ii) decisão ab-rogatória superveniente ${ }^{47}$.

A predeterminação ab-rogatória acontece sempre que o tratado já estabeleça um termo final de vigência, ou seja, desde o momento da concepção do tratado as partes já firmam também o momento final de sua vigência. José Francisco Rezek destaca que a condição resolutiva para o seu encerramento poderá se dar por diversas razões, entre as quais, veja-se: pela extinção de outro tratado que a condicione ou que Ihe seja estruturante; pela exaustão operacional do trabalho e a queda do número de partes ${ }^{48}$.

A decisão ab-rogatória superveniente, por sua vez, acontece quando as partes, durante a vigência do tratado, resolvem extingui-lo. Isto é, como "bilateral o tratado, a vontade uniforme de ambas as partes poderá sempre desfazê-lo, ainda que interrompendo o curso de um prazo certo de vigência - e, pois, em circunstâncias nas quais a denúncia unilateral seria inconcebível"49.

47 REZEK, José Francisco. Op. cit., p. 103-107.

48 Idem, p. 104.

49 Idem, p. 105. 
No que se refere a essa espécie de extinção, vale apontar que poderá o tratado dispor que a ab-rogação superveniente poderá acontecer por maioria. A validade desse ato estará condicionada à previsão antecipada desta regra, por intermédio de uma cláusula competente. Para fins de clareza e didática, representa dizer que no tratado já haverá uma cláusula a qual preveja que o acordo poderá ser encerrado pela vontade da maioria dos signatários ${ }^{50}$. Entrementes, quando não presente cláusula deste naipe, então não se poderá consentir como válida a ab-rogação por maioria. Em uma situação dessas, ocorrerá não uma ab-rogação por maioria, mas sim a exteriorização de diversas denúncias. Não se podem confundir as duas situações, como bem aclarado por José Francisco Rezek $^{51}$.

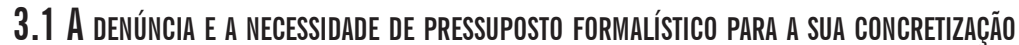

A denúncia, como dito anteriormente, representa a extinção do tratado para a sua esfera. É a demonstração da vontade de uma das partes para extinguir o tratado para a sua alçada. Francisco José Rezek aduz que a "denúncia é um ato unilateral, de efeito jurídico inverso ao que produzem aquelas duas figuras: pela denúncia, manifesta o Estado sua vontade de deixar de ser parte no acordo internacional" $" 52$.

No tocante ao momento da retirada, esse é um assunto delicado. Diversos tratados determinam que a retirada poderá ocorrer a qualquer momento, não havendo a necessidade de qualquer solenidade para tanto. Todavia, nada impede que o próprio texto normativo ajustado estabeleça que somente poderá ocorrer a retirada depois de um determinado período ou ainda que deverá existir uma determinada solenidade.

A imperiosidade de solenidade para a retirada de uma das partes é o que se acostuma chamar de pré-aviso. Consoante José Francisco Rezek, dá-se o nome de pré-aviso para a estipulação "de um prazo de dilação dos efeitos da denúncia: o Estado retirante não previne seus pares de que vai denunciar; ele efetivamente denuncia o tratado, mas só se encontra desobrigado após o curso do período previsto" ${ }^{\prime \prime 3}$.

Quanto à formalização, Rezek assevera que a denúncia materializa-se por um instrumento jurídico formal (notificação, carta ou instrumento em si) sob a forma escrita, a fim de transmitir a vontade da parte de encerrar o compromisso para seus fins. Segundo o autor, "trata-se de uma mensagem de governo, cujo destinatário, nos pactos bilaterais, é o governo da parte co-pactuante. Se

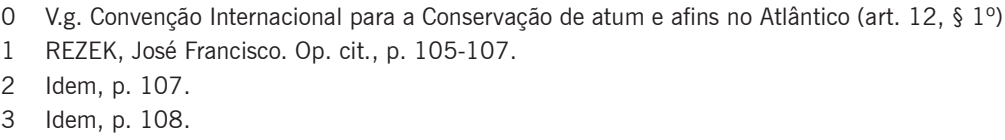


coletivo o compromisso, a carta da denúncia dirige-se ao depositário, que dela fará saber às demais partes ${ }^{\prime \prime 54}$.

No que se refere à possibilidade jurídica da denúncia parcial, esse assunto foi tratado pela Convenção de Viena, conquanto de modo perfunctório. Para o encontro dessa resposta, é indispensável que se examine se a cláusula a ser denunciada poderia ser alvo de reservas no momento da adesão. Caso não pudesse ser objeto de reservas, por conseguinte inexiste qualquer margem para dúvidas acerca da impossibilidade de denúncia parcial. Por outro lado, caso pudesse ser objeto de reservas uma determinada cláusula, e se o presente acordo ainda está aberto à adesão, então plenamente possível. Do contrário, conforme alenta José Francisco Rezek, deveria ocorrer a denúncia integral e, posteriormente, a admissão novamente da parte ao tratado, o que per si desprestigiaria qualquer lógica razoável ${ }^{55}$.

Em que pese todas essas questões inerentes à denúncia, a grande celeuma que se faz presente é a necessidade ou não de algum pressuposto formalístico para a validade de uma denúncia na realidade brasileira. Ou seja, é impreterível sob a égide do atual ordenamento jurídico que haja a aprovação prévia do Congresso Nacional para a formalização da denúncia pelo Estado?

No Direito brasileiro, a questão de saber se o Presidente da República pode denunciar sozinho, sem a autorização do Congresso Nacional, um tratado é debatida desde 1926, data em que ocorreu a primeira posição governamental sobre o assunto.

À época, Clóvis Bevilaqua, na figura de consultor jurídico do Itamaraty, foi instado a se manifestar sobre a competência do governo e realizou o seu opinativo, no dia 5 de julho de 1926. Cita-se um trecho de seu parecer, o qual propugnou pela possibilidade de denúncia feita pelo Presidente, prescindindo a autorização do Congresso Nacional:

Em face da Constituição Federal pode o Poder Executivo, sem ouvir o Congresso Nacional, desligar o País das obrigações de um tratado, que, no seu texto, estabeleça as condições e o modo da denúncia, como é o caso do Pacto da Sociedade das Nações, art. 1ำ última parte. Essa proposição parece evidente, por si mesma. Se há no tratado uma cláusula, prevendo e regulando a denúncia, quando o Congresso aprova o tratado, aprova o modo de ser o mesmo denunciado; portanto, pondo em prática essa cláusula, o Poder Executivo apenas exerce um direito que se acha declarado no texto aprovado pelo Congresso. O ato da denúncia é meramente administrativo. A denúncia do tratado é modo de executá-lo, porquanto numa de suas cláusulas se acha consignado o direito de o dar por extinto. ${ }^{56}$

54 Idem, p. 109

55 Idem.

56 Clóvis Bevilaqua apud REZEK, José Francisco. Op. cit., p. 110-111. 
Celso D. de Albuquerque Mello assevera que a denúncia não precisa da aquiescência do Poder Legislativo, pois, segundo o autor, "a denúncia de um tratado não necessita no Brasil de aprovação do Legislativo, o que é mais um argumento para mostrar que o tratado não pode ser equiparado a uma lei" ${ }^{\prime 57}$. Ou seja, seguindo um raciocínio lógico, como o jurista Celso D. de Albuquerque Mello entende que para a aprovação não há necessidade do Poder Legislativo, logo, via de consequência, para a denúncia também não há a necessidade.

José Francisco Rezek, por sua vez, coaduna da opinião de que tanto o Poder Executivo quanto o Poder Legislativo poderá denunciar o tratado, sem haver a necessidade de uma opinião conjunta. Segundo o autor, "o ânimo negativo de um dos dois poderes políticos em relação ao tratado há de determinar sua denúncia, visto que significa o desaparecimento de uma das bases em que se apoiava o consentimento do Estado" ${ }^{\prime 58}$.

Apesar das abalizadas opiniões jurídicas suscitadas, não se pode compreender e nem admitir, frente à legislação brasileira, que se confira legitimidade e poder ao Presidente da República para formalizar a denúncia de forma isolada.

Como se sabe, na seara jurídica, o regime jurídico aplicável a um instituto é composto de regras e princípios jurídicos. Nos tratados internacionais, tal situação não é diferente. Por conseguinte, infere-se que o regime jurídico dos tratados é integrado por normas jurídicas (princípios e regras). Existem alguns princípios jurídicos aplicáveis que decorrem do contexto constitucional brasileiro.

O fundamento para a impossibilidade da atitude unipessoal do Poder Executivo em denunciar um tratado que foi aprovado pelo Congresso Nacional encontra óbice no princípio da separação dos poderes, mais precisamente na harmonia que deve existir entre eles.

O princípio da harmonia entre os Poderes está previsto no art. $2^{\circ}$ da Constituição da República Federativa de 1988 ao prescrever que "são poderes da União, independentes e harmônicos entre si, o Legislativo, o Executivo e o Judiciário".

Conforme ensina José Afonso da Silva, a harmonia estabelece em razão das "normas de cortesia no trato recíproco e no respeito às prerrogativas e faculdades a que mutuamente todos têm direito. De outro lado, cabe assinalar que nem a divisão de funções entre os órgãos do poder nem sua independência são absolutas" ${ }^{\prime \prime 59}$.

O fundamento para a existência do equilíbrio entre os Poderes está no estabelecimento de um sistema de freios e contrapesos (checks and balances),

57 MELLO, Celso. D. de Albuquerque. Op. cit., p. 259.

58 REZEK, José Francisco. Op. cit., p. 112.

59 SILVA, José Afonso da. Curso de direito constitucional positivo. 31. ed. São Paulo: Malheiros, 2008. p. 110. 
para alcançar o objetivo, consoante José Afonso da Silva, "do equilíbrio necessário à realização do bem da coletividade e indispensável para evitar o arbítrio e o desmando de um em detrimento do outro e especialmente dos governados" ${ }^{\prime \prime 0}$.

Kildare Gonçalves Carvalho destaca que o referido princípio, o qual foi idealizado principalmente por Montesquieu, ganhou "consistência no século $\mathrm{XVIII}$, para enfraquecer o poder absoluto dos monarcas que deram unidade política ao Estado soberano do século XVII. De fato, a dispersão medieval desaparece com o nascimento do Estado moderno, quando o poder se concentra no monarca, cuja autoridade se amplia" ${ }^{161}$.

Desse modo, a partir do momento em que a Constituição da República previu que a aprovação de um tratado internacional depende da participação do Congresso Nacional, não se pode admitir que a retirada, exclusão, do Estado dependa da vontade independente do Poder Executivo.

Assentir com o pensamento de liberdade do Poder Executivo para a realização dos atos de desligamento de um Estado em um tratado internacional é consentir com o arbítrio, o qual se diferencia de liberdade legal condicionada. Ou seja, liberdade incondicionada é arbítrio. Liberdade condicionada é discricionariedade.

Poder-se-ia aventar que a separação de poderes e o controle recíproco, nesse caso, poderiam gerar um enfraquecimento do Estado. Em contraponto, para rechaçar esse pensamento, Kildare Gonçalves diz que o raciocínio é ao contrário, pois "para que um grupo de pressão possa abusar do poder estatal, em seu próprio interesse, não basta que ele se volte para apenas uma autoridade, mas tenha que conquistar os diferentes poderes do Estado, o que dificulta a sua ação" ${ }^{\prime 2}$. Nuno Piçarra, na mesma direção, relata de maneira briosa que "as instituições democráticas devem estar ao serviço da opinião da maioria do eleitorado e não ao serviço de um conglomerado de grupos de pressão"63.

Assim, com esteio nessas dificuldades ora citadas, dessume-se que a preservação do interesse público ${ }^{64}$ norteador da atuação do Congresso Nacional e do Presidente da República será melhor preservado por intermédio da atuação conjunta entre os Poderes Legislativo e Executivo no momento da denúncia de um tratado internacional. Representa uma maior segurança jurídica ao Estado em si, bem como a todos os cidadãos que integram o Estado.

60 Idem.

61 CARVALHO, Kildare Gonçalves. Direito constitucional. 14. ed. Belo Horizonte: Del Rey, 2008. p. 168.

62 Idem, p. 169

63 PIÇARRA, Nuno. A separação dos poderes como doutrina e princípio constitucional. Coimbra: Coimbra, 1989. p. 233.

64 Acerca do interesse público e principalmente para afastar qualquer diminuição da superioridade do interesse público sobre o interesse privado, vide a clássica passagem do Professor Celso Antônio Bandeira de Mello (MELLO, Celso Antônio Bandeira de. Curso de direito administrativo. 25. ed. São Paulo: Malheiros, 2008. p. 58-86), bem como a recente obra de Emerson Gabardo (GABARDO, Emerson. Interesse público e subsidiariedade. Belo Horizonte: Fórum, 2009. p. 251-324). 
No entanto, além do princípio da harmonia dos poderes, destaca-se o princípio da simetria, ou também conhecido como princípio do paralelismo das formas, como fundamento para repudiar qualquer denúncia sem a volitividade do Poder Legislativo.

O princípio da simetria representa que os pressupostos formalísticos utilizados para a elaboração de um instituto deverão ser utilizados para o desaparecimento desse instituto também. Isto é, o raciocínio esposado pelo princípio do paralelismo das formas nada mais representa do que uma lógica coerente a ser adotada tanto para a elaboração de um ato quanto para a exclusão desse mesmo ato.

Paulo Bonavides aborda o princípio do paralelismo das formas e explica que por tal princípio "resulta que um ato jurídico só se modifica mediante o emprego de formas idênticas àquelas adotadas para elaborá-lo. Ou, em outras palavras, aplicado o conceito à reforma constitucional: o órgão que fez a Constituição é o único apto a alterá-la" ${ }^{\prime \prime 5}$.

Em diversas oportunidades, o Supremo Tribunal Federal já decidiu com supedâneo no princípio em tela, consoante se desprende do aresto colacionado a seguir:

Afronta os princípios constitucionais da harmonia e independência entre os Poderes e da liberdade de locomoção norma estadual que exige prévia licença da Assembleia Legislativa para que o Governador e o Vice-Governador possam ausentar-se do País por qualquer prazo. Espécie de autorização que, segundo o modelo federal, somente se justifica quando o afastamento exceder a quinze dias. Aplicação do princípio da simetria. (ADIn 738, Rel. Min. Maurício Corrêa, Julgamento em 13.11.2002, Plenário, DJ de 07.02.2003) ${ }^{66}$

Consoante se desprende da intelecção do princípio em lume, pode-se asseverar que o princípio da simetria tem sido constantemente utilizado pelo Supremo Tribunal Federal para diversos julgamentos, o que per si reflete a juridicidade do princípio para interpretar as mais variadas situações fáticas ${ }^{67}$.

Por tais razões, não se pode conceber que para a ratificação de um tratado internacional haja a imprescindibilidade de aprovação por parte do Congresso Nacional, consoante interpretação sistemática do art. 84, VIII, e art. 49, I, da Constituição Federal de 1988 e ulteriormente a ratificação do Poder Executivo com a emissão do competente decreto, entrementes, para o desfazimento do tratado por ato unilateral (denúncia) baste tão somente um decreto do Poder Executivo sem qualquer baliza ou aval por parte do Congresso Nacional.

65 BONAVIDES, Paulo. Op. cit., p. 106

66 Em sentido similar: ADIn 775-MC, Rel. Min. Celso de Mello, Julgamento em 23.10.1992, Plenário, DJ de 01.12.2006

67 Para demonstrar tais reiteradas decisões, citam-se os seguintes julgados: MS 24.665/DF; RE 487.475-AgRg/ RJ; ADIn 2.730/SC, ADIn 3.930/RO, RE 396.970-AgRg/SP, entre outros. 
Se o Congresso Nacional aprovou o tratado internacional, então ele deverá aprovar também a denúncia do Estado, sob pena de o princípio da harmonia dos Poderes e o princípio da simetria serem afrontados.

Até porque, os referidos princípios deverão ser interpretados de acordo com a Constituição. Ou seja, preconiza-se uma interpretação conforme a Constituição, nos dizeres de Luis Roberto Barroso, que representa o dever de interpretar de modo adequado "dos valores e princípios constitucionais, ou a declaração de inconstitucionalidade de uma das interpretações possíveis de uma norma ou, ainda, a declaração de não incidência da norma a determinada situação de fato, por importar em violação da Constituição"68. Portanto, pela técnica de interpretação constitucional suscitada, devem ser apreciadas as prescrições da legislação de acordo com a Constituição da República de 1988.

Para complementar os argutos fundamentos já expendidos, valioso recorrer ainda à busca do significado das normas de acordo com os ditames da Filosofia do Direito para uma hermenêutica construtiva e para defender assim a necessidade de participação do Poder Legislativo para a celebração da denúncia. Sobre o assunto, Celso Lafer explica:

No paradigma da Filosofia do Direito, a busca do significado, por meio de uma hermenêutica construtiva, que na aplicação das normas leve em conta os fins do Direito, pressupõe que estes correspondam a algum critério de justiça que legitime a ação do juiz, pois o hiato entre a verdade e o significado é preenchido pelo reconhecimento da importância do valor na experiência jurídica. Com efeito, e com base neste pressuposto deontológico - que funciona como vindicatio actionis diante da impossibilidade da validatio cognitions de um juízo determinante - que o juiz procura encontrar soluções satisfatórias, em cada caso concreto, através de um não à letra da lei e de um sim ao seu espírito, para assim impedir a aplicação rígida e irrefletida das normas jurídicas. Em outras palavras, na interação entre Fato e Valor flexibiliza-se diante de uma problema concreto a norma, buscando-se no entanto manter a coerência do sistema do Direito (o ordenamento) através de um reforço permanente de conciliar a razão com a justiça. ${ }^{69}$

Portanto, resta indubitável que o Poder Legislativo não pode ser afastado da análise e do controle político na denúncia feito pelo Estado brasileiro em um tratado internacional. Acerca do tema, Manuel Aragon expõe sobre a necessidade de vinculação do controle político no Estado de Direito contemporâneo, in verbis:

Sabido que a constituição do Estado de Direito contemporâneo vincula juridicamente todo o poder estadual, que ela própria funda originariamente, fica excluída a possibilidade de a função política ser considerada juridicamente livre e

68 BARROSO, Luis Roberto. Curso de direito constitucional contemporâneo. São Paulo: Saraiva, 2009. p. 302.

69 LAFER, Celso. A reconstrução dos direitos humanos: um diálogo com o pensamento de Hannah Arendt. São Paulo: Companhia das Letras, 1988. p. 283. 
constitucionalmente desvinculada, pois todo e qualquer acto estadual carece de habilitação constitucional. ${ }^{70}$

\section{CONCLUSÃO}

Após a exposição tracejada neste trabalho, conclui-se que hodiernamente os tratados internacionais são uma fonte primordial para o direito internacional.

Apesar dessa relevância ímpar, insta apontar que o procedimento para a elaboração e vigência dos tratados encontra diversas peculiaridades de acordo com a legislação brasileira, mormente no que se refere à interpretação constitucional dos dispositivos aplicáveis, razão pela qual é indispensável que haja o devido debate acadêmico, a fim de ocorrer o devido amadurecimento nas interpretações jurídicas e, principalmente, o encontro de soluções adequadas do ponto de vista jurídico.

Todavia, ainda que o procedimento para a elaboração e vigência desperte interesses e debates, consoante arrazoado neste ensaio, é de enfatizar uma grande problemática que permeia os tratados firmados pelo Brasil, qual seja, a necessidade ou não de participação do Poder Legislativo para a concretização da denúncia.

Conquanto existam brilhantes vozes defendendo a "autonomia" do Poder Executivo para denunciar sozinho um tratado internacional, é de se destacar que tal conclusão não pode ocorrer em conformidade com a Constituição da República Federativa de 1988.

Os princípios da simetria, também denominado de paralelismo das formas, e da harmonia dos poderes não permitem que o Poder Executivo manifeste a vontade do Estado brasileiro, sem a oitiva do Poder Legislativo, sob pena de desferir duas medidas desiguais para situações similares, quais sejam: comprometimento do Estado frente a outros Estados e organismos internacionais.

Posto isso, infere-se que tanto a entrada do Estado brasileiro em um tratado internacional quanto a denúncia para a sua retirada são importantes e reclamam a participação do Poder Legislativo, o que per si reclamam que os mesmos pressupostos formalísticos sejam respeitados.

\section{REFERENNCIAS}

ACCIOLY, Hidelbrando; SILVA, Geraldo Eulálio do Nascimento; CASELLA, Paulo B. Manual de direito internacional público. 17. ed. São Paulo: Saraiva, 2009.

ARAGON, Manuel. Constitucion y el control del poder. Buenos Aires: Ciudad Argentina, 1995.

70 ARAGON, Manuel. Op. cit., p. 253 
ARAúJO, Luís Ivani de Amorim. Curso de direito internacional público. 7. ed. Rio de Janeiro: Forense, 1992.

BACELLAR FILHO, Romeu Felipe. Reflexões sobre direito administrativo. Belo Horizonte: Fórum, 2009.

BARROSO, Luis Roberto. Curso de direito constitucional contemporâneo. São Paulo: Saraiva, 2009.

BONAVIDES, Paulo. Curso de direito constitucional. 19. ed. São Paulo: Malheiros, 2006.

CAPRA, Fritjof. As conexões ocultas: ciência para uma vida sustentável. Trad. Marcelo Brandão Cipolla. São Paulo: Cultrix, 2002.

CARVALHO, Kildare Gonçalves. Direito constitucional. 14. ed. Belo Horizonte: Del Rey, 2008.

CRETELLA JÚNIOR, José. Comentários à Constituição Brasileira de 1988. Rio de Janeiro: Forense, 1992.

FERREIRA, Pinto. Comentários à constituição brasileira. São Paulo: Saraiva, v. III, 1992.

FERREIRA FILHO, Manoel Gonçalves. Comentários à Constituição Brasileira de 1988. São Paulo: Saraiva, v. II, 1992.

GABARDO, Emerson. Interesse público e subsidiariedade. Belo Horizonte: Fórum, 2009.

LAFER, Celso. A reconstrução dos direitos humanos: um diálogo com o pensamento de Hannah Arendt. São Paulo: Companhia das Letras, 1988.

LIMA, Sérgio Mourão Corrêa. Tratados internacionais no Brasil e integração. São Paulo: LTr, 1998.

MEDEIROS, Antonio Paulo Cachapuz de. O poder de celebrar tratados: competência dos poderes constituídos para a celebração de tratados à luz do direito internacional, do direito comparado e do direito constitucional brasileiro. Porto Alegre: S. A. Fabris, 1995.

MELLO, Celso Antônio Bandeira de. Curso de direito administrativo. 25. ed. São Paulo: Malheiros, 2008.

MELLO, Celso D. de Albuquerque. Curso de direito internacional público. 15. ed. Rio de Janeiro: Renovar, 2004.

PIÇARRA, Nuno. A separação dos poderes como doutrina e princípio constitucional. Coimbra: Coimbra, 1989.

PIETRO, Maria Sylvia Zanella di. Direito administrativo. 21. ed. São Paulo: Atlas, 2008. PIOVESAN, Flávia. Direitos humanos e o direito constitucional internacional. 9. ed. São Paulo: Saraiva, 2008.

REZEK, José Francisco. Direito internacional público: curso elementar. 11. ed. São Paulo: Saraiva, 2008.

SILVA, José Afonso da. Curso de direito constitucional positivo. 31. ed. São Paulo: Malheiros, 2008. 